\title{
Quaternized Polyamidoamine Dendrimers as Novel Gene Delivery System: Relationship between Degree of Quaternization and Their Influences
}

\author{
Jung Hoon Lee, Yong-beom Lim, Joon Sig Choi, Myung-un Choi, Chul-hak Yang, and Jong-sang Park* \\ School of Chemistry \& Afolectar Engineering, Seoul Kational Lniversitw, Seoul 151-742, Norea \\ Received Julv 25, 2003
}

\begin{abstract}
Quaternary ammonium groups were introduced to Starburst polyamidoamine (PAMAM) dendrimers for a gene carrier. These quaternary dendritic carriers exhibited reduced cytotoxicity on $293 \mathrm{~T}$ cells compared to parent dendrimers examined and their transfection efficiency were similar with parent dendrimers. Quaternization could be a promising tool to improve properties of dendrimers as a gene delivery carrier
\end{abstract}

Key Words : Gene delivery, PAMAM. Quatemary amine, Cytotoxicity

\section{Introduction}

Dendrimers are highly branched polymers with welldefined and three-dimensional structure. Starburst polyamidoamine (PAMAM) dendrimers consist of tertiary amines in core. primary amines on a surface and amide backbone. They have the captured interest of researchers because of successful use for nonviral gene delivery ${ }^{2.3}$ and conmercially available polymers as whole (amine-terminated groups) or half (carboxylate-terminated groups) generation. Basic dendrimers e.g.. poly(propylene imine) and PAMAM were modified to quaternary amine groups for a $\mathrm{pH}$-sensitive controlled release system. ${ }^{4}$ a dendritic anion conductor ${ }^{5}$ effective antimicrobials ${ }^{6}$ and a photosensitizer for photodynamic therapy. ${ }^{7}$ Here. we report starburst PAMAM dendrimers (generation 4 . containing 62 interior tertiary amines and 64 exterior primary amines) possessing quaternary amine groups as novel nonviral gene delivery sy'stem. An important feature of quaternized PAMAM (QPAM) dendrimers was that primary amines which had significant toxic effect to cell membrane ${ }^{8-11}$ could be decreased. Exchange of primary amines and tertiary amines to quaternary ammonium salts could be expected to reduce the cytotoxicity giving hydrophilic nature. Moreover their charge density could be increased by methylation of interior tertiary amine groups so that the amount for complexation with DNA could be reduced.

\section{Meterials and Methods}

Meterials. PAMAM G4 (Starburst). Methyl iodide. anhydrous N.N-dimethlyformamide (DMF) and PEI (average molecular weight $25 \mathrm{kDa}$ ) were purchased from Aldrich (Milwaukee. WI). PGL3-control vector (plasmid DNA) was purchased from Promega (Madision. WI). Fetal bovine serum (FBS) and Dubecco's modified Eagle's medium (DMEM) were purchased from GIBCO (Gaithersburg. MD).

Synthesis of partially quaternized PAMAM (QPAM).

Corresponding author. Tel: +82-2-880-6660; Fax: +82-2-8775110 ; e-mail: pfịspark äplaza.snu.ac.ks
The solvent (methanol) dissolved PAMAM was evaporated and dried prior to reaction. PAMAM $(0.1 \mathrm{~g} .0 .7 \mathrm{mmol})$ dissolved in DMF $(0.5 \mathrm{~mL})$ were added to appropriate methyl iodide ( 0.2 equiv. 0.5 equiv. and 0.8 equiv. per mole of the possible number of tertiary amino groups and primary amino groups) diluted in DMF $(0.5 \mathrm{~mL})$ and stirred for $24 \mathrm{~h}$ at room temperature or $37^{\circ} \mathrm{C}$. The resulting clear solution was precipitated in diethyl ether and the residues were vacuum-dried for overnight. After dried residues were redissolved in $1 \mathrm{~mL}$ of water. the solution was placed into a dialysis membrane (SpectraPor. MwCO 6000-8000). and dialyzed against $2 \mathrm{M} \mathrm{NaCl}$ and pure water in succession. Purified QPAMs were dried and obtained as white powder. ${ }^{\mathrm{l}} \mathrm{H} \mathrm{NMR}\left(300 \mathrm{MHz}, \mathrm{D}_{2} \mathrm{O}\right) \delta 2.46$ (br m. $\mathrm{CH}_{2} \mathrm{CO}$ ). 2.65-3.1 (br m. NCH${ }_{2} \mathrm{CH}_{2}$ and $\mathrm{CH}_{2} \mathrm{CH}_{2} \mathrm{CONH}_{2}$ ), $3.17-3.22$ (br s. $\mathrm{CH}_{2}$ ). 3.47-3.32 (br m. $\mathrm{CH}_{2} \mathrm{~N}^{-}$) 3.71 $\mathrm{CONHCH}_{2}$ ). The level of quaternization was determined by ratio intergration of peak at $3.2 \mathrm{ppm}$ versus theoretically calculated integration of full quaternization

Atomic force microscopy (AFM). Atonic force microscopy (Nanoscope IIIa system. Digital Instruments. Inc. Santa Barbara. CA) was used for imaging the morphology of complexes at $4: 1(\mathrm{~N} / \mathrm{P}$ or $+/-)$ ratio. Complex were formed at $1 \mu \mathrm{g} / \mathrm{mL}$ plasmid DNA concentration in water for $30 \mathrm{~min}$. Samples were applied to freslly cleaved mica and absorbed on the mica for $5 \mathrm{~min}$. After excess fluid on the mica was wicked off using filter paper. samples on mica were dried at room temperature prior to imaging. The image mode was set to tapping mode and average scan speed was $1.5 \mathrm{~Hz}$.

Dynamic light scattering (DLS) measurement. The size of complexes was determined using a BI-200SM Goniometer (Brookhaven instruments corporation. Holtsvile. NY. USA) with a Lexel laser model 95 argon laser (100 $\mathrm{mW}$ output power at a wavelengh of $514.5 \mathrm{~nm}$ ). Correlator. PD2000 (Precision Detectors) was used and the scattering angle was $90^{\circ} \mathrm{C}$

Cytotoxicity assay. MTT assay was performed for the cytotoxicity assay. $293 \mathrm{~T}$ cells $\left(1 \times 10^{4}\right.$ cells $/$ well $)$ were seeded in 96-well plate and grown in $95 \mu \mathrm{L}$ DMEM containing $10 \%$ FBS. supplying $5 \% \mathrm{CO}_{2}$ at $37^{\circ} \mathrm{C}$ for overnight. Cells were exposed QPAMs. PAMAM G4 and PEI $25 \mathrm{kDa}$ as controls 
with various concentration for $\mathrm{I}$ day. After that, they were added $25 \mu \mathrm{L}$ of MTT stock solution $(5 \mathrm{mg} / \mathrm{mL})$ and incubated for $2 \mathrm{~h}$, then added $100 \mu \mathrm{L}$ of extraction buffer $(20 \% \mathrm{w} / \mathrm{v}$ of SDS in $50 \%$ DMF, pH 4.7$)$. Absorbance was measured at $570 \mathrm{~nm}$ after overnight incubation.

Cell transfection. 293 T cells were seeded in 24-well plate at a density of $5 \times 10^{4}$ cells/well and grown in DMEM containing $10 \%$ FBS for 1 day. 'Two $\mu \mathrm{g}$ of DNA per well was complexed dropping into QPAMs in FBS free DMEM for 30 min at roon temperature. Complexes in FBS free DMEM were transfected to the cells with replacing old medium. Following $4 \mathrm{~h}$ incubating cells, culture medium was exchanged to fresh DMEM containing 10\% FBS. After incubating for 2 days, cells were washed with PBS with removing the growth medium and lysed for $30 \mathrm{~min}$ at room temperature adding reporter lysis buffer. Luciferase activity was measured in a LB 9507 luminometer (Berthold, Germany) and protein content was measured by BCA assay (Pierce, Rockford, IL).

\section{Results and Discusstion}

Synthesis of QPAMs. QPAMs (Figure 1) with various degrees of quaternization were synthesized by partial methylation of tertiary amine groups and primary amine groups. The level of quaternization was determined by the method proton integration values at $3.2 \mathrm{ppm}$ in ${ }^{1} \mathrm{H}$ NMR $\left(300 \mathrm{MHz}, \mathrm{D}_{2} \mathrm{O}\right)$ that were divided by theoretically calculated integration values of fully quaternized dendrimers. Approximately 10\% (0.1-QPAM), 50\% (0.5-QPAM) and 70\%(0.7QI'AM) of quaternary ammonium salts were produced at PAMAM G4.

Characterization of QPAMs-complexed polyplexes. To visualize their morphology of the polyplexes between QP'AMs and DNA, the particles were observed by atomic force inicroscopy (AFM) and the images are shown in Figure 2. The single population particles were formed respectively, and their shapes were assumed to be several tens nano-sized spherical particles.

Wolfert et al. reported that cationic polymers containing quaternary ammonium groups showed efficient complex formation with smallest diameters, in according to studying polymers possessing among primary, tertiary and quaternary amino groups on the properties of complexes formed with DNA. ${ }^{12}$ To verify that QPAMIDNA complexes are strong and efficient enough, the particle size of these complexes were performed using dynamic light scattering (DLS). Figure 3 shows the particle size of QPAM dendrimers prepared in water. Interestingly, relatively large particles were detected at $\mathrm{N} / \mathrm{P}$ ratios of 0.5 (0.1-QPAM). $2(0.5-$ QPAM) and 1 (0.7-Q1'AM). Probably at these ratios, QPAM molecules functioned as a crosslinker for plamid molecules yielding large aggregates. This is seen from the neutralization between DNA and QPAMs by canceling the net charge ${ }^{l s}$ and the resulting minimized the charge-to-charge repulsion between complex particles might cause the large particles. ${ }^{14}$ Increase of dendrimers $D N A$ values up to 10

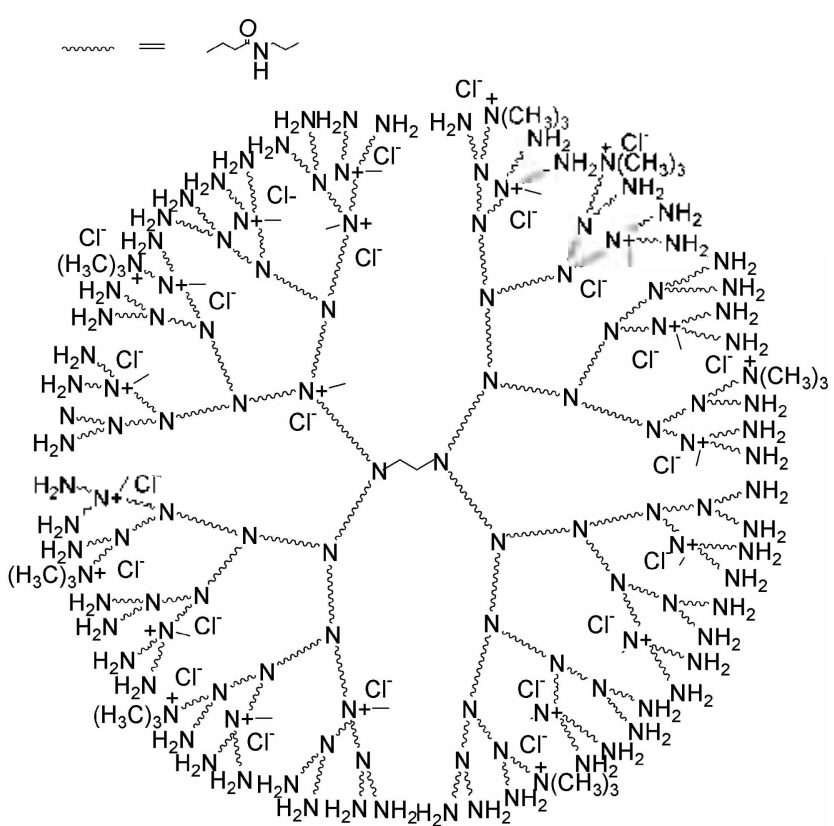

Figure 1 . The structure of QPAM. Primary amines and tertiary amines of PAM $\triangle M$ were converted into quaternary amine groups at a degree of $10 \%(0.1 \mathrm{Q}-\mathrm{P} / \mathrm{M}) .50 \%(0.5 \mathrm{Q}-\mathrm{P} / \mathrm{M})$ and $70 \%(0.7 \mathrm{Q}-$ PAM).

resulted in recharging of the polyplexes and decreasing in their size as sinall as $56 \mathrm{~nm}$.

Cytotoxicity issue depends on the degree of quaternization. Cell viability studies were performed on $293 \%$ cells using an MT'T assay. ${ }^{15}$ Relative cell viability (\%) versus dendrimer concentration is shown in Figure 4. The minimum viability of cells exposed to the solution of QPAMs at various concentration was $75 \%$ relative to controls, indicating low cytotoxicity of QPAMs compared to PAMAM and PEI. The cells exposed all the Ql'AMs were more viable than those of parent dendrimers, and a positive correlation between cell viability and degree of quaternization was detected; PAMAM $<0.1$-QPAM $<0.5$-QPAM $<0.7$-QPAM with cell viability in according to the degree of quaternization. In this study, P'El was found to be polymer with the highest cytotoxicity. The polycations characterized rigid and global structure (e.g. l'AMAM dendrimers) were found to be low toxicity because of the difficulties to attach to membranes or to uptake to cells causing cytotoxicity, whereas polymers with linear or branched and flexible structure (e.g. PEI) showed higher cell damaging effects." It was also reported that the quaternization of the P'El polymer resulted in a decrease of toxicity because transformation of an water soluble polymer resulted in an improved safety profile. ${ }^{10}$ Quaternary ammonium groups are always charged and strongly hydrophilic thus, unmodified PAMAM dendrimers composed of primary amine groups and tertiary amines groups may not be as hydrophilic as modified PAMAM with quaternary ammonium groups. 'These quaternary ammonium groups modified dendrimer-based delivery systems are supposed to be useful for reduction of the toxicity of PAMAM dendrimers. 
(A)

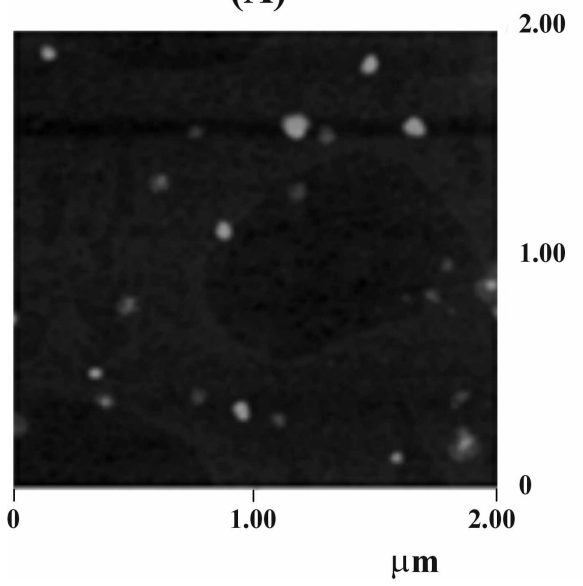

(C)

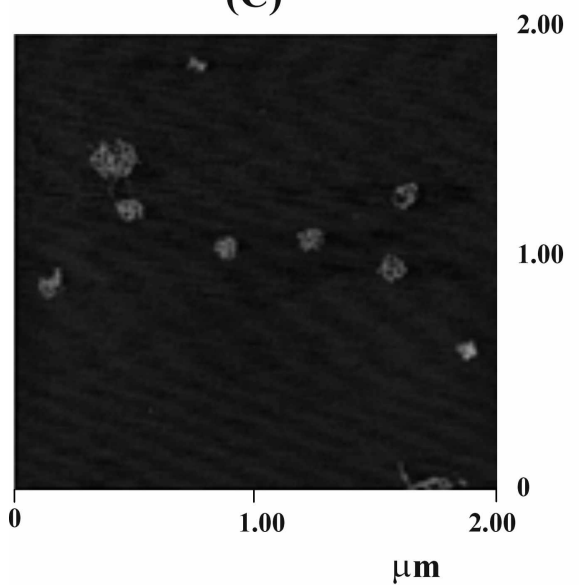

(B)
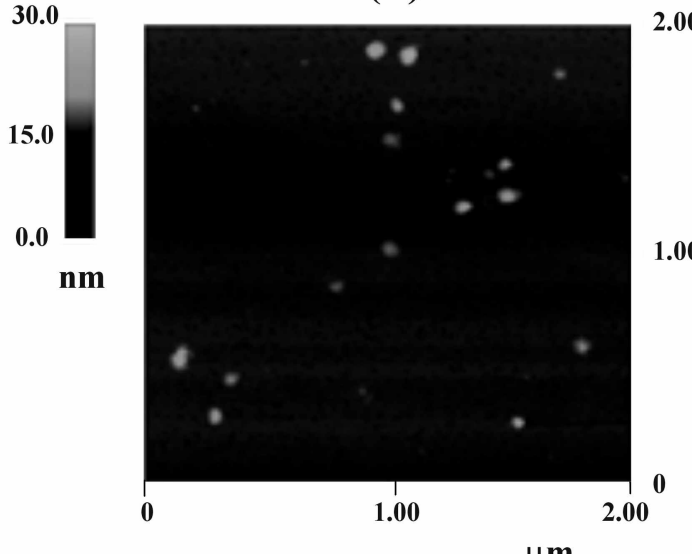

(D)

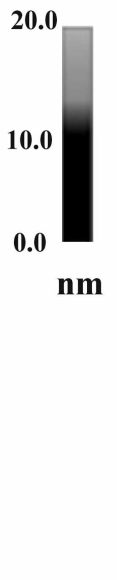
$\mathbf{0 . 5 0}$

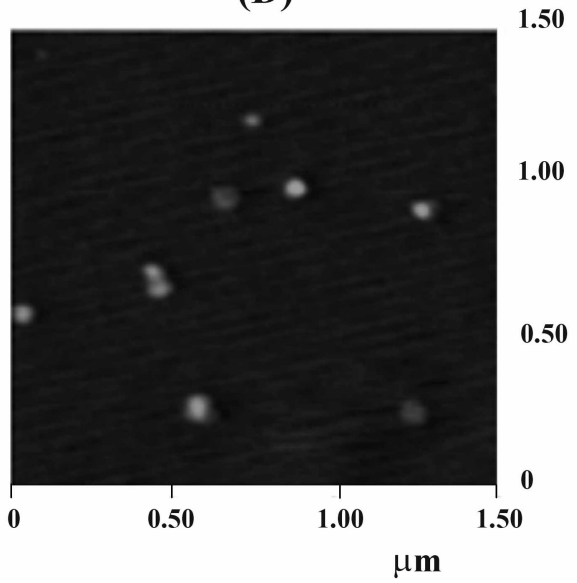

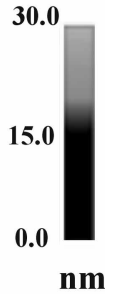

$\mu \mathbf{m}$ 1.50

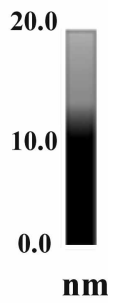

$\mathbf{n m}$

Figure 2. Morphology of particles imaged by atomic force microscopy (AFM) at charge ratio $(+/-)=4.0$ or . $\mathrm{V}$ ( ratio $=4.0$. (A) PAMAM G4/plasmid IONA particles. (B) 0.1-QPAM/plasmid IJNA particles, (C) 0.5-OPAM/plasmid IONA particles (I) 0.7-OPAM/plasmid I)NA particles. The $N / P$ ratio was calculated from the number of amines and of QPA.Ms and the number of phosphate groups of $D \times A$.

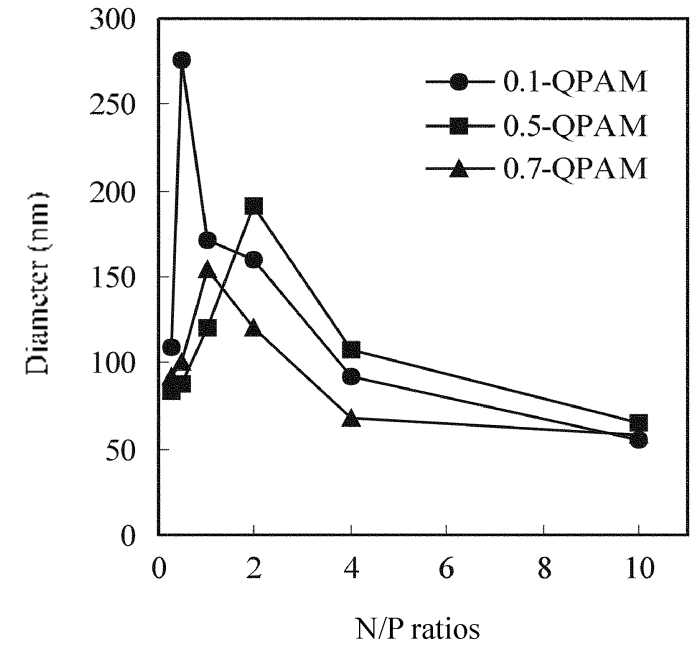

Figure 3. Particle sizes of quatemized PAMAM derivalives determined by dynamic light scaltering (DLS). Diameters indicate the sizes which dendrimers formed in $5 \mu \mathrm{g} / \mathrm{mL}$ of plasmid DNA concentration.

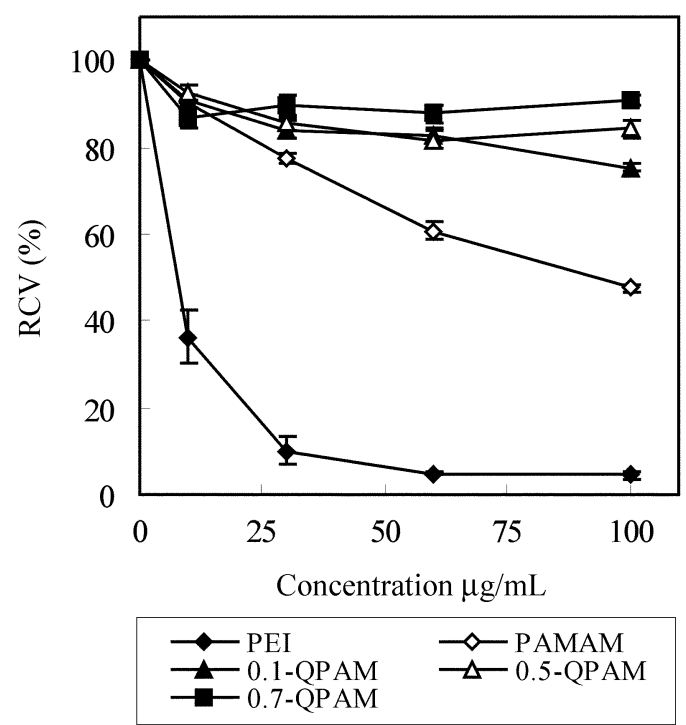

Figure 4. Cytotoxicity assay on $293 \mathrm{~T}$ cell line for the study of the eflect of quaternization to PAMAM (G4 and Pl:I $25 \mathrm{kI}$ ) as a control. Relative cell viability $(\mathrm{R}(\mathrm{V}, \%)$ is expressed as a percent of viable cells divided by untreated cells. 


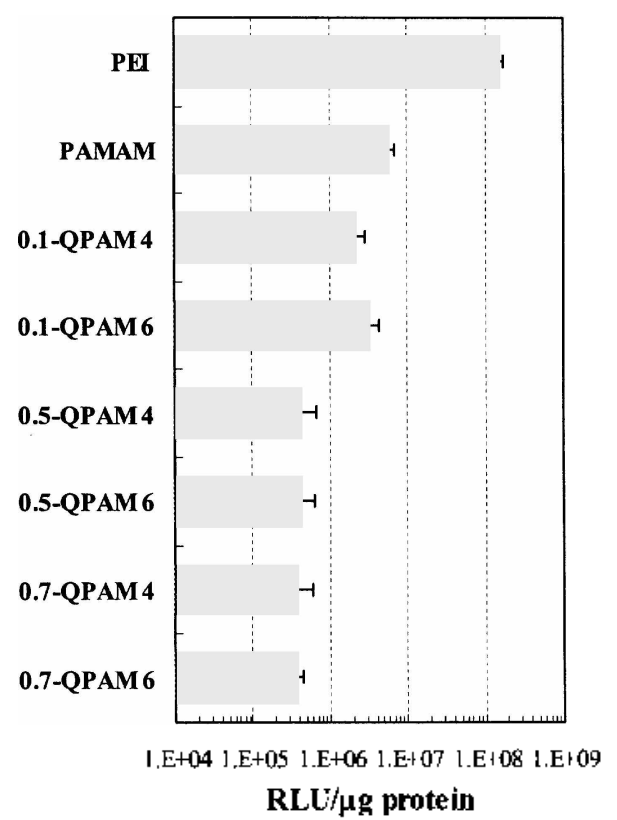

Figure 5. Transtection efficiency on $293 \mathrm{~T}$ cell line. Cells were translected with IJNA of $2 \mu \mathrm{g}$ in the absence of serum for $4 \mathrm{~h}$. Transgene expression was measured $48 \mathrm{~h}$ postlranslection. Vumbers indicate No ratios of dendrimersiDNA. Data are determined in triplicate and expressed relative liglst unit (RL . I) per Hg prolein.

Transfection efficiency in vitro. The quaternization effect of PAMAM on transfection is shown in Figure 5 . We have transfected 293'] cells with plasmid DNA, observing luciferase activities. The levels of expression in the case of 0.1 Q]'AM were in the same order of magnitude as those obtained with nonmodified PAMAM. Using 0.5-QPAM and $0.7-Q P A M$, the result of quaternization exhibited an observed approximately 10-fold reduction of transfection levels comparing to PAMAM. Quaternized polycations are so completely charged at any $\mathrm{pH}$ as a strong polyelectrolyte that they lack $\mathrm{pH}$ resposiveness on the endosome, perhaps via the so-called proton sponge mechanism. ${ }^{17}$ Therefore, the reduced transfection activity associated with quaternized polycation may involve relatively poor access to nucleus.

\section{Conclusion}

In summary, we have introduced a series of quaternized P'AMAM by simple and efficient methylation of PAMAM G4. The complexes were highly efficient in condensation of plasmid DNA. Although the transfection efficiency of QPAM derivatives except to 0.1-QPAM is lower by an order of magnitude than PAMAM G4, our systems have the merit of much lower cytotoxicity comparing to parent dendrimers by producing hydrophilic nature. The influence of quatenization on the polycations is currently under investigation as our further studies.

Acknowledgements. We acknowledge the support of this work by the Korea Research Foundation (2000-015DP0285).

\section{References}

1. Tomalia. D. A.: Baker. H.: Dewald. J.: Hall. M.: Kallos. G.: Martin. S.: Roeck. J.: Ryder. J.: Smith. P. Pollm. J. 1985. 17. 177.

2. Kukowskit-1.atallo, J. I:: [Bielinska A. [I.: Johnsom, J.: Spindler. R.: Tomalia. D. A.: Baker. I. R.. Jr. Proc. Natl Acad. Sot dS.A 1996. 93.4897 .

3. Eichınan. J. D.: Biclinska. A. U.: Kukowska-Latallo. I. F.: Baker. I. J. R. Pham So. Teck. Todan: 2000. 3.2.32.

4. Sidcratou. 7.: Tsiourvas, D.: Palcos. C. M. I.omgmmir 2000. 16. 1766.

5. Gong. A.: Liu. C.: Chen. Y.: Zhang. X.: Chen. C.: Xi. F. Aforomol Rupid Commun. 1999. 20.492.

6. Chetr. C. Z.: Beck-Tan. V. C.: Dhurjati. P.: van Lyk. T. K.: LaRossa. R. A.: Cooper. S. L. Biomacromolecules 2000. /. 473.

7. Nishiyama N.: Stapurt. II. R.: Thang. G. D.: Takasu. D.: Jiang. D. L.: Nalgano. T.: Nida T.: Kallaoka K. Bioconiug (hem. 20113, It. 58

8. Dekie. L.: loncheva. V.: Dutruel. P.: Schacht. E. H.: Barrett. L.: Scymour. L. W. J. Contr: Release 2000. 65. 187.

9. Fischer. D.: Lib. Y.: Ahlemeycre. B.: Kricglsteinc. I.: Kissel. T. Biomaterials 2003,24.1121.

10. Kim. S.: Choi. J. S.a Jang. IL. S.: Suh, J L.: Park. J. S. BuH. Kontom Chent. Soc 2001. 22. 1069 .

1]. Choi. J. H.: Choi. J. S.: Suh. H.: I'ark. J. S. Bull. komean Chem. Soc. 2001. 22. 46 .

12. Woltert. V. A.: Dash. P. R.: Vazarova. O.: Oupicky. D.: Scymour. I, W: Smatt. S.: Strohalm. J.: Ulbrich. K. Biocoming (hem. 1999. 17. 593.

13. Yaroslawov. A. A.: Sukhishvili. S. A.: Oholsky: (). L.: Yareslanovad E. G.: Kabanov. A. V.: Kabanow. V. A. FEBS Lett. 1996. 384. 177.

14. Jong. J. H.: Song. S. H.: Lim. D. W.: Lec. H.: Park. T. G. J. Contr: $R^{2} \cdot e^{\prime}\left(t 50^{\prime} 2001,73,391\right.$.

15. I Jansen. M. 13. J. Ammumologict thethods 1989. 179. 203.

16. Brownlic. A.: Ucheglou. I. F.: Schatrlein. A. (i. Controlled Release Society 20th Anntal Weeting Proceedings 2002. 105 .

17. Zuber. G.: Dauty. E.: Nothisen. M.: Belguise. P.: Behr. J. P. Adl. Dratg Defivery Rev 2001. 52. 245. 